\title{
"For Your Safety"
}

\section{Effects of camera surveillance on safety impressions, situation construal and attributed intent}

\begin{abstract}
Based on the assumption that monitoring technology in environmental settings impacts people's state of mind and subsequent perceptions, the current study examines the influence of security camera's on safety perceptions and citizen wellbeing. Participants watched a video of city streets that featured (versus not featured) security cameras. In the camera condition, their safety ratings were significantly higher than in the camera-less (control) condition. In addition, the camera condition caused more positive ("safe") interpretations of an ambiguous situation than the control condition. Finally, results suggest that attributed intent underlying camera usage is a key construct to reckon with when considering camera placement. In discussing these findings, the conditions under which camera surveillance contributes to citizen wellbeing are elaborated on.
\end{abstract}

Keywords: security cameras, safety perceptions, environmental design, perceived intent

\section{Introduction}

In many western societies, closed-circuit television (CCTV) or video surveillance has become a fact of life. Many societies aim to safeguard their citizens against evildoers by installing watchful eyes, and probably none more so than the UK. According to BBC Newsnight television program, the City of London has a total number of cameras of 619 , on a population of about 9000 - almost 69 cameras per 1000 inhabitants. Another area within Greater London, Wandsworth, has 1113 cameras, which is more than the number of cameras of the police departments of Boston, Johannesburg, San Francisco, and Dublin City Council combined [BBC, 2009]. Nonetheless, many other European countries appear to be following suit. Although accurate estimations are largely missing, the omnipresence of security cameras at airports, in bus and train stations, large shops, malls, offices, industrial areas, etc., are an indication that 'big brother' is closely watching over its citizens.

The dominant goal of video surveillance is the prevention of crimes and misdemeanors such as burglary, theft, pickpocketing, intimidation, violence, and vandalism, and, thus, maintaining an environment in which citizens feel safe and sound. There are various indications in literature, however, suggesting that the mere presence of cameras has additional psychological effects on citizens, which usually receive limited attention by policy makers and law enforcers. For instance, in lab studies camera presence has been shown to promote prosocial behaviors [e.g., Van Rompay, Vonk, \&

adfa, p. 1, 2011.

(C) Springer-Verlag Berlin Heidelberg 2011 
Fransen] as the resultant of people's need for approval in front of an 'audience' [e.g., Latané, 1981; Leary \& Kowalski, 1990]. Additionally, cameras may elicit suspicion (Why am I being watched?) and trigger 'acting out' behaviors (e.g., hooligans acting out in front of cameras, suggestive of defiance and rebellion). In other words, how people react to camera placement seems to vary depending on contextual influences such as the type of setting and people's attributions of intent.

By consequence, the conditions under which cameras actually induce feelings of safety are likewise debated. Whereas some have found that CCTV increases feelings of safety [Gill \& Spriggs, 2005], others have argued that this applies only to those among the public who already feel safe [Ditton, 2000]. In line with such an argument, cameras could also make people more aware of safety threats, especially those already ill at ease or suspicious, and may therefore negatively influence safety perceptions [Gill \& Spriggs, 2005]. Inspired by this controversy, the current research aims to shed light on the influence of CCTV camera presence (in a Dutch city center) on feelings of safety and environmental perceptions. In addition, it seeks to explore the role of attributed intent as a potential mediator of effects of camera surveillance on safety impressions.

\subsection{Environmental design and perception}

In addition to research highlighting social feelings and interpersonal consequences of camera surveillance (e.g., helping behavior; Van Rompay et al., 2009), another line of research that is highly relevant to current undertaking concerns priming research in social psychology [Aarts \& Dijksterhuis, 2003; Aarts, Dijksterhuis, \& De Vries, 2001; Kay, Wheeler, Bargh, \& Rossa, 2004]. For instance, Kay et al. [2004] showed that people who had been exposed to objects common to the domain of business (e.g., fountain pens, conference tables and brief cases) tended to interpret ambiguous social situations as more competitive in nature than those who had not been exposed to such stimuli. Similarly, primed individuals also behaved more competitive by keeping more money to themselves in a so-called 'ultimatum game'. Apparently, exposing people to objects associated with specific norms or values (e.g., self-interest, competition) may cause people to behave in line with such context-specific norms.

Along a similar line of reasoning, Aarts and Dijksterhuis [2003] showed that exposure to pictures of library environments (in which silence or keeping one's voice down so as not to disturb other is considered appropriate) made participants talk less loud, again showing that people tend to behave in line with associations tied to objects. These results show that objects in an environment may steer an individual's perceptions and behaviors in line with meanings associated with these stimuli. However, as hinted at, it is an open question whether cameras foremost evoke safety perceptions or whether they rather induce perceptions and feelings related to vandalism and related transgressions. In the latter case, cameras would rather elicit negative affect and feelings of unease.

Arguably, which of these two routes prevails also depends on people's attributions; perceiving camera surveillance as a sign of care and genuine concern for civilian safety arguably triggers a qualitatively different experience than framing camera presence 
as a sign of distrust towards citizens and 'big brother'-like control. The study presented in the next section was designed to address these research questions.

\section{Method}

\subsection{Participants and design}

Seventy-six students of two Dutch universities took part in this study; 52 participants were female, and 24 were male (Mean age: 22 years). The study employed a onefactor, between-participants design. The independent variable "Camera presence" consisted of two levels, present versus absent (control).

\subsection{Procedure}

Participants entered the lab and were told that they would evaluate a city environment based on video footage presented on a LCD screen. They were randomly assigned to one of the two conditions. In the Camera present condition they were shown video footage recorded while walking through the streets of a small local city. The footage comprised streets in the city center, the shopping area, and several alleys (all outdoor settings). All of these streets had CCTV cameras installed. In the Camera absent (control) condition, participants were shown the same footage, but this time all frames in which CCTV cameras were visible were removed. This was done to create two identical videos, the only difference between them being the visibility of cameras. Afterwards, participants filled out a questionnaire comprising the dependent measures.

\subsection{Dependent measures}

Affective evaluation of environment. In order to measure participants' overall affective evaluation of the environment, they indicated on 5-point rating scales the extent to which they considered the environment depicted in the video safe, agreeable, cozy, warm and orderly (alpha $=.68)$.

Interpretation of ambiguous situation. In order to test the presumed effect of camera surveillance on participants' interpretation of an ambiguous situation, participants provided a story-script to a scene involving an encounter between a man and woman in a foggy setting (see Figure 1). Subsequently, participants' responses were categorized into four categories ranging from 'very negative' to 'positive' by three independent coders (Cohen's kappa's $>$.72).

Attributed intent. In order to measure participants' 'attributed intent' underlying camera placement, they indicated to what extent they agreed with the statements 'policy makers have a keen eye for things going on here' and 'policy makers have taken adequate measures to make these streets safe' $(r=.55)$.

Familiarity with city streets. In order to control for feelings of familiarity (covariate), participants indicated (yes/no response) whether they were familiar with the city streets depicted. 


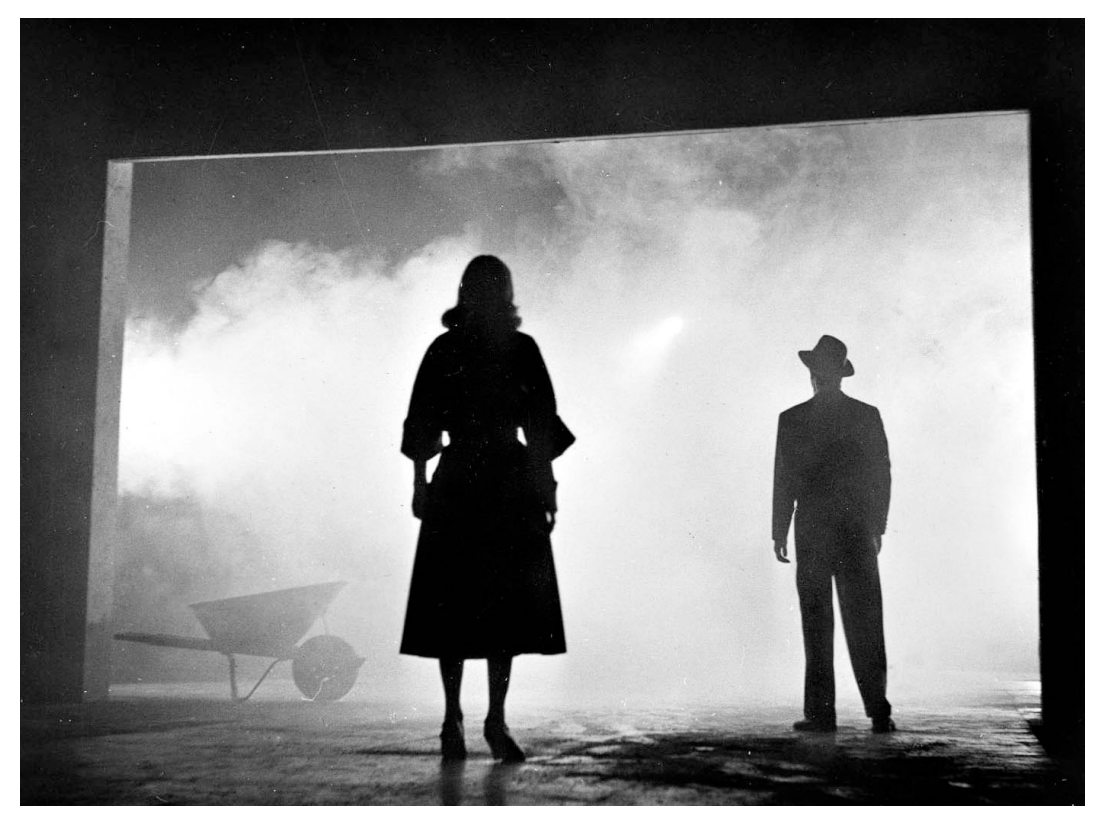

Fig. 1. Ambiguous situation portrayal

\section{Results}

A univariate analysis of variance with camera presence as independent variable, affective evaluation of the environment as dependent variable, and familiarity with city streets as covariate, revealed a significant effect of camera presence; $F(1,73)=4.43$, $p<.05$, showing that participants in the video surveillance condition entertained a more positive affective evaluation of the city center $(\mathrm{M}=2.50, \mathrm{SD}=.68)$ compared to participants in the no-camera, control condition $(\mathrm{M}=2.22, \mathrm{SD}=.43)$.

In line with these findings, the same analysis, but this time with interpretation of ambiguous situation' as dependent variable, showed that participants in the camera condition framed the ambiguous scene in more positive terms compared to the control condition $(\mathrm{F}(1,73)=5.03, \mathrm{p}<.05)$. To illustrate, participants in the camera surveillance condition were more likely to provide positive, or affectively neutral, evaluations of the depicted scene (e.g., "A man and a woman have taken a walk at night and have come across an industrial workplace", "A man and a woman have a rendezvous in a stable on a foggy evening") compared to the no-camera condition (e.g., "A young woman is being chased by a perpetrator", "There has been an explosion and a man and woman are watching events unfold from a distance"). 
Finally, a significant effect emerged on 'attributed intent' $(F(1,73)=33.66, p<$ $.001)$, showing that participants in the video surveillance condition were much more likely to infer that law enforcers in the city act on behalf of citizen safety $(M=3.68$, $\mathrm{SD}=.52)$ compared to participants in the no-camera condition $(\mathrm{M}=2.65, \mathrm{SD}=.95)$.

In order to test whether camera presence positively impacts participants' affective evaluation of the environment because it is interpreted as a sign of good intent, mediation analyses (Baron \& Kenny, 1986) were conducted. In addition to the already established effect of camera surveillance on participants' affective evaluation of the environment, regression analyses also revealed a significant effect of the mediator (attributed intent) on the dependent variable (affective evaluation of the environment; $\beta=.55, \mathrm{t}(73)=5.63, p<.001$. For mediation to apply, the effect of the independent variable (camera surveillance) should become non-significant, whereas the mediator should remain significant, when both are entered simultaneously in the regression analysis as predictors of the dependent variable 'affective evaluation of the environment'. The respective regression analysis showed this to be the case; the effect of camera presence was no longer significant; $\beta=.10, \mathrm{t}(73)=.84, p=.40$, whereas the effect of the mediator (attributed intent) remained significant; $\beta=.60, \mathrm{t}(73)=5.13, p$ $<.001$.

Hence, camera surveillance positively affects the affective evaluation of the environment because it is perceived as a sign of positive, well-meant intent.

\section{Conclusions and discussion}

These combined findings underscore the potential of camera surveillance to positively impact citizens' affective experience comprising safety feelings and feelings of being 'at ease'. In line with these impressions (generated by camera presence), participants framed an ambiguous interaction in more positive terms compared to those in the nocamera condition. This finding indicates that effects of camera presence extend beyond mere perceptions and may also impact social evaluations and related behaviors. Hence, in follow-up research, it would be interesting to study whether effects of camera presence also transpire in actual behaviors. For instance, if camera presence enacts more positive social evaluations, does this also transpire in a more open, forthcoming attitude towards strangers, and thus perhaps in heightened willingness to initiate, for instance, small talk?

Importantly, the results presented also underscore the importance of people's inferences with respect to camera presence. That is, in the current study, camera presence elicited positive inferences reflecting law enforcers and policy makers (e.g., "They know what is going on, they know what they are doing, and they do it with citizen safety in mind"). Arguably, such inferences came natural in the context central to current undertaking (i.e., city streets). An interesting question to be addressed by follow-up research is what would happen in situations wherein the rationale for camera presence is less obvious (e.g., in indoor environments such as retail centers or town halls, or in public parks). That is, when and where is camera presence framed as a 
sign of distrust or control rather than an outcome of genuine concern for citizen safety?

To address these and related questions, different types of environments (varying in the extent to which camera presence therein is perceived as natural) could be pitted against each other. Alternatively, framing of camera presence could be varied within one and the same environment. For instance, accompanying camera presence we may sometimes find video surveillance signs stating "For your safety", "Warning, video surveillance in progress", or "Smile, you are being videotaped". How do such different messages varying in verbal aggressiveness ("Warning!"), indication of genuine concern ("For your safety"), or humor ("Smile...") guide inference making? Insights in effects of contextual variables (e.g., type of environment) and framing of camera presence may very well make the difference between a suspicious, irritation-prone, anti-social civilian and a citizen feeling at ease, cared for, and open towards others.

\section{$5 \quad$ References}

1. Aarts, H., Dijksterhuis, A. (2003). The silence of the library: Environment, situational norm, and social behavior. Journal of Personality and Social Psychology, 84(1), 18-28.

2. Aarts, H., Dijksterhuis, A., De Vries, P. (2001). On the psychology of drinking: Being thirsty and perceptually ready. British Journal of Psychology, 92(4), 631-642.

3. Baron, R. M., \& Kenny, D. A. (1986). The moderator-mediator variable distinction in social psychological research: Conceptual, strategic, and statistical considerations. Journal of Personality and Social Psychology 51(6), 1173-1182.

4. BBC (2009). http://news.bbc.co.uk/2/hi/uk/8159141.stm.

5. Ditton, J. (2002). Crime and the city: Public attitudes to CCTV in Glasgow. British Journal of Criminology, 40, 692-709.

6. Gill, M., \& Spriggs, A. (2005). Assessing the impact of CCTV. Home Office Research Study 292. London: Her Majesty's Stationary Office.

7. Kay, A. C., Wheeler, S. C., Bargh, J. A., \& Rossa, L. (2004). Material priming: The influence of mundane physical objects on situational construal and competitive behavioral choice. Organizational Behavior and Human Decision Processes, 95(1), 83-96.

8. Latané, B. (1981). The psychology of social Impact. American Psychologist, 36(4), 343356.

9. Leary, M. R., \& Kowalski, R. M. (1990). Impression management: A literature review and two-component model. Psychological Bulletin, 107(1), 34-47.

10. Van Rompay, T. J. L., Vonk, D. J., \& Fransen, M. L. (2009). The eye of the camera: Effects of security cameras on prosocial behavior. Environment and Behavior, 41(1), 60-74. 